\title{
Research and Practice on the Cultivation of Good Habits of Chinese College Students
}

\author{
Ying Wang \\ Changchun Guanghua University
}

Keywords: Big Data, College Students, Habits Cultivation

\begin{abstract}
In the era of highly-developed digital media technology, as a Chinese college counselor, we should pay more attention to guiding and cultivating the sound personality and good habits of college students, which not only related to personal integrity and spiritual heritage, but also related to the whole society and the spirit of the nation. With the growth of college students, the good quality will benefit for life. Therefore, improving the moral cultivation of contemporary college students, cultivate and help contemporary college students to develop good habits and sound personality is an indispensable lesson in university education, it is also an important part of the education system.
\end{abstract}

\section{Develop the Habits of Integrity}

Since ancient times, honesty and trustworthiness is a person's conduct, but also a person's moral foundation. If a person speaks without a letter, it is unbearable; if a nation is a country without words, it will be cast aside. Some people do not lie seriously, can lie in many countries is the most intolerable deceptive behavior and people are more willing to work with the liar.

Integrity is the life of the "gold signs" no matter what time will not fade and reduce the weight, therefore, first of all should have the integrity of the quality. Integrity is a natural law and it is a law of life cannot be violated. Students do not speak integrity, the results will be canceled degree certificate; teachers do not speak integrity, the results will be mistaken children; school does not speak integrity, and ultimately will be ruined. So, we should start from the freshman, it should be about a few aspects to start, to cultivate the integrity of students to develop.

First of all, the integrity of education into the important work of student education, according to the specific circumstances of each school, timely into the personnel training program. The integrity of college students should not just stay in the moral level, but should rise to the general education, so that every student to learn and understand the importance of integrity education.

Second, the school needs to establish a complete set of network integrity assessment system, at any time to track records, integrity information will be backed up in the student's personal electronic files, in order to prepare as the school first selection and campus "Star Star" example of the power of supporting materials. But also in the assessment process clearly punish and punish the system and the relevant provisions of the rules, so that honest and trustworthy students get timely recognition and affirmation, but also to those students who are misconduct behavior due to criticism and punishment should be done Rewards and punishments.

Again, should be honest education and campus cultural activities of the organic combination, and refinement to each of the campus activities, so that students' habits of good habits from each of the activities of each link to gradually develop and make it institutionalized, normalized.

Finally, in the process of developing good faith habits, the need to build integrity of the family, integrity class style, integrity school spirit. So that parents and schools to form an interactive and interconnected, concerted efforts to consolidate and strengthen the results of education to promote students to consciously recognize the importance of good faith habits.

College students in the university during the integrity of consciousness, integrity and integrity of the integrity of the formation of the behavior, not only related to the spirit of the school's integrity, but also related to the formation of the integrity of the whole society. And thus enhance the sense of 
social responsibility of each student to improve the moral cultivation of each student is an important part of college education. So that students develop good faith habits for the students have been beneficial and harmless, students will enter the community into the community will be good faith habits to work, married will be passed on to the next generation of good faith, so the integrity of habits to develop education is the University An indispensable lesson.

\section{Develop Thanksgiving Habits}

"Drinking water thinking source" is to tell us to know "Thanksgiving blessing." If the student can feel life with a grateful heart, then his heart will never have a shadow will always be filled with sunshine. On the contrary, if you forget the gratitude, it is equivalent to forget the most beautiful life of emotion, is to miss the beautiful scenery of life. At present, college students are not a minority of health unhealthy, because their own habits to develop very few, if you can often pregnant with a grateful heart, nourish the mind to make the mind more healthy, positive face every day a good habit , Life will be colorful.

In every person's life, will certainly get a lot of people help. If someone else has helped you, you should be grateful. Nowadays, every day a college student should know that Thanksgiving parents, Thanksgiving school, Thanksgiving country, no parents in exchange for money will not have good learning conditions; no school learning environment creation will not have the ability to learn knowledge to improve Platform; no country's peace and stability will not have a variety of material and information to enjoy.

Therefore, to develop college students Thanksgiving habits need to use the power of science and technology, such as newspaper, news and other media to vigorously promote and carry forward the deeds of Thanksgiving, and Thanksgiving topics into the college classroom, but also from time to time on a wide range of " Thanksgiving "as the theme of a large series of educational activities, so that the idea of Thanksgiving deep into the hearts of every student, so that the concept of these positive energy in the majority of students widely circulated.

\section{Develop Habits of Helping Others}

It is a kind of behavioral habit, a simple traditional virtue. With the development of social science and technology, to bring us convenient and also makes people become more indifferent between the ruthless. Especially now 90 after the basic are the only child, has been dependent on a variety of electronic products to survive, little concern around people and things, it is difficult to find people around whether there are difficulties.

Now, although we can see in the university campus, there are individuals who like to help others to help others in the difficulties, but most of the students still have selfishness, only personal interests. In order to allow students in the university life to their youth to leave some good memories, to cultivate students' good habits is imperative. Help others happy themselves, when others need help, can lend a helping hand, which is as the basic character of college students, there is no utilitarian attempt, do not ask any return is to make the other out of trouble, life is more beautiful. This is the charm of helping others.

There are many kinds of habits in the world, good habits can save lives and bad habits can hurt their lives. In the limited university is the time to cultivate some good habits of the students, remove some bad habits, which is the University should do the obligation to cultivate helpful habits through the following aspects.

First, create a helpful campus environment, a campus full of love. The campus is a big family, in this big family, if everyone has love in their hearts are willing to offer helpful, others will not stand aside to ignore. Help each other and then the campus will become more harmonious and warm.

Second, in the campus to establish "help others" model characters. So that students can feel this behavior in the various corners of the campus are taking root, blossom results; so that students see the power of example, always remind themselves to cultivate a high degree of quality, embodied in every little thing, each one details. 
Third, try to create a good person, good atmosphere and environment. In the campus, the class provides students with the opportunity to care for others, or to help others after the students to talk about feelings and experiences. Learn what you have learned when you are helpful. And the typical deeds edited into a book, left to the new students to read, play the role of inheritance and encouragement.

Fourth, the organization of volunteer teams, from time to time out of the school, to the community for volunteer service activities, to expand the spirit of helping people for the impact. So that students in the volunteer service activities more compassionate, more for the sake of others, students of mutual infection, mutual influence; feel mutual concern, mutual attentive kind of warmth, so as to cultivate the quality of helping others.

In short, helping others develop to engage everyone to learn from each other. Through the school system of publicity, guidance and education, so that students in the university campus will help others continue to inherit and carry forward, thus affecting a group of a group of students, so that the spirit of helping people always remember in our contemporary college students Mind, as they grow and become a great spiritual power on the road, to lead and spur them not forward.

\section{Develop Habits of Respecting for Other People}

Respect for others is a virtue, but also a basic principle of getting along with others, occupying a very important position in character. Respect for others is often a manifestation of a person's cultivation, but also a measure of the level of a person's ideological standards. Talking with people talking and doing things directly affect the evaluation of others and their attitude. It is a very important thing that college students can learn to respect others in the university to develop good habits of respecting others. Among them, learn to listen is one of the important ways to respect others.

For young people, listening also means learning to communicate with the mind. This is because listening to it is only a way of talking, but it is in the relationship between people contains a huge force. At present, college students just lack of respect is the habit of others. They lack the respect for their parents' life, lack of respect for the friendship between friends, lack of respect for knowledge acquisition, lack of respect for school rules and regulations, lack of respect for the law, lack of respect for social responsibility and so on. To get rid of these bad habits, it is necessary to cultivate students to develop their own good habits of respect for others.

Only respect others, others will always appreciate you. You meet the spiritual needs of others, others will meet your spiritual needs, want to harvest what please first sow the seeds in order to look forward to harvest.

\section{Develop Thrift Habits}

With the improvement of living standards, extravagance and waste in college students has become a common phenomenon. Today's campus we can still see the water flow of the faucet, people do not go out lights, did not eat leftovers, unused stationery and clothing. Graduating class students throw away the garbage can still see seven or eight new clothes. This phenomenon not only affects the cultivation of young people's personality, but also breeds a lot of bad habits, leading to the community after the encounter more setbacks.

Thrift is our traditional virtues of the Chinese nation, many rich are from poor to rich, from beginning to end are very frugal. Thrifty is both a respect for the workers who create wealth, but also cherish the hard earned money of their parents. Thrifty can not only make the various things at home, but also improve the ability of young people to live independently and feel the work of their parents the results are hard to come by. Students through the habit of saving thrift can make their own real reality, to take the initiative to understand the importance of money and hard to come by, will eventually help form a good habit of thrift. 


\section{Optimize the Character and Develop Habits}

Shaping the perfect character is the first lesson of life. People often say: character determines fate, sowing a character, it is necessary to harvest a fate. People often regard the character as born, so there is a nature of a say, but the history of experience and told us: character is still the result of self-cultivation. As long as they see themselves gradually optimize the bad character, life is still in their own hands.

Character is like a navigator that can be a person to the success of the other side and you can also push a person to the abyss of failure. So the habit of cultivating the optimized character should be part of the university education. Personality for each person to decide a lot of things, such as interpersonal relationships, marriage choice, life status, career choice, business success or failure and so on. Fundamentally determine the future direction of life.

\section{Conclusion}

"Behavior determines habits, habits shaping character, character achievement life". The qualified contemporary college students must develop good habits, shape integrity, excellent personality and learn knowledge, practice skills in college and then they can achieve brilliant life in the future. In the context of highly developed information media technology, we must fully understand and use the large data, the new media brought many conveniences of the times to maximize the guidance of college students to develop good habits to help them create a sound personality, which is our arduous task and glorious mission, as a college counselor in the ranks of an ordinary member, we are duty-bound, we must go all out!

\section{References}

[1] Sun Yunxiao. "Habits to develop a way" Zhejiang Literature and Art Publishing House 2016.3

[2] Campus culture, network culture and college students' network culture literacy interaction [J]. Wu Hanmei, Chen Enping, Lin Liyuan, Gao Changhua. China's out-of-school education. 2016 (33)

[3] College students network culture literacy and campus culture, network culture interaction analysis [J]. Wu Hanmei, Chen Enping, Lin Liyuan, Gao Changhua. Education modernization. 2016 (36)

[4] Internet on the moral factors and causes of college students analysis [J]. Wang Guoliang, Liu Lijuan. Journal of Tibet Institute for Nationalities (Philosophy and Social Sciences) .2007 (04)

[5] Chang Xuqing. Analysis on the mechanism of network information security education in colleges and universities - Based on the data survey of students' network usage in North University of China[J]. Journal of North University. 2013 (03)

[6] Analysis on the Current Situation of College Students' Network Morality and Educational Countermeasures - Based on the Questionnaire Survey of 9 College Students in Wuhan [J]. Wang Yuan, Ding Zhenuo, Chen Huawen, Gao Xing. School Party Building and Ideological Education. $2013(10)$

[7] The formation mechanism of college students' social responsibility and the improvement strategy [J]. Wei Jinping, Feng Shigang. Journal of Hebei Normal University (Philosophy and Social Sciences). 2013 (04)

[8] Delphi method in the screening of healthy lifestyle evaluation of college students in the application of research [J] .Wang Dong, Xing Xiaohui, Chen Qing. China General Practice. 2010 (22) 